\title{
Effect of peppermint oil and its microemulsion on necrotic enteritis in broiler chickens
}

\author{
Hend K. Sorour ${ }^{1}$ (D), Reham A. Hosny ${ }^{1}$ (D) and Dalia M. A. Elmasry² (D) \\ 1. Reference Laboratory for Veterinary Quality Control on Poultry Production, Animal Health Research Institute, \\ Agricultural Research Center, Giza, Egypt; 2. Nanotechnology Research Unit, Animal Health Research Institute, \\ Agricultural Research Center, Giza, Egypt. \\ Corresponding author: Dalia M. A. Elmasry, e-mail: dr_daliaelmasry@yahoo.com \\ Co-authors: HKS: Hend_rosemarry@yahoo.com, RAH: rehamhosny87@yahoo.com \\ Received: 20-09-2020, Accepted: 28-12-2020, Published online: 23-02-2021
}

doi: www.doi.org/10.14202/vetworld.2021.483-491 How to cite this article: Sorour HK, Hosny RA, Elmasry DMA (2021) Effect of peppermint oil and its microemulsion on necrotic enteritis in broiler chickens, Veterinary World, 14(2): 483-491.

\begin{abstract}
Background and Aim: Clostridium perfringens is one of the multiple drug-resistant intestinal pathogens causing necrotic enteritis disease, leading to great economic losses in poultry farms. This study aimed to evaluate the potential use of peppermint oil and its microemulsion (ME) as an alternative to antibiotics to control necrotic enteritis in broiler chickens.

Materials and Methods: Peppermint oil ME formulation (15\% oil/water) was prepared and characterized by zeta potential, Fourier transform infrared, high-resolution transmission electron microscopy, and liquid chromatography-mass spectrometry (LC-MS/MS). The minimal inhibitory concentrations of the peppermint oil and its ME were investigated. A total of 80 commercial one day old Arbor Acres broiler chickens were randomly assigned to four groups of 20 birds each. The four groups were the negative control, positive control, peppermint oil $(0.5 \mathrm{~mL} / \mathrm{mL}$ water $/ 10$ days old), and its ME $\left(0.25 \mathrm{~mL} / \mathrm{mL}\right.$ water $/ 10$ days old) groups. C. perfringens was orally provided at concentration of $1 \times 10^{8} \mathrm{CFU} / \mathrm{mL}$ on days 14 , 15 , and 16. Clinical signs and mortality were observed daily. Growth performance, gross lesions and cecal samples were investigated and examined on days 21,28 , and 35 .
\end{abstract}

Results: Peppermint oil ME formulation has a polydispersity index, zeta potential and droplet size of $0.234,-24 \mathrm{mV} \pm 4.19$, and $29.96 \pm 1.56 \mathrm{~nm}$, respectively. LC-MS/MS analysis of oil and ME revealed common presence of phenolic compounds such as rosmorinic $(360.31 \mathrm{~g} / \mathrm{mol})$, chlorogenic acid $(354.31 \mathrm{~g} / \mathrm{mol})$, hesperidin $(610.56 \mathrm{~g} / \mathrm{mol})$, and luteolin 7-O- $\beta$ glucuronide $(462.1 \mathrm{~g} / \mathrm{mol})$. The treated groups with peppermint oil and ME showed lower lesions, mortality and colonyforming units in addition to higher growth performance $(\mathrm{p}<0.05)$ ompared to the positive control group.

Conclusion: Our study suggests the potential efficacy of peppermint oil and ME in the reduction of necrotic enteritis lesions and C. perfringens count.

Keywords: broiler chicken, feed conversion ratio, microemulsion, nanotechnology, necrotic enteritis, peppermint oil.

\section{Introduction}

Necrotic enteritis is a global disease threatening broiler chicken farms. It is characterized by sudden death, decrease in body weight (BW), and diarrhea [1,2]. Clostridium perfringens is a causative agent of necrotic enteritis and is considered as a normal flora in the intestinal tract of apparently healthy birds [3-5]. It has different types (A, B, C, D, and E) that are producing various types of toxins (alpha, beta, epsilon, and iota). There are many predisposing catalyzing factors having a role in the proliferation of $C$. perfringens along the intestinal tract, such as dietary components, immune suppression through vaccination, sudden change of feed, coccidial infection, and fasting [6,7]. Misuse of antimicrobial growth

Copyright: Sorour, et al. Open Access. This article is distributed under the terms of the Creative Commons Attribution 4.0 International License (http://creativecommons.org/licenses/by/4.0/), which permits unrestricted use, distribution, and reproduction in any medium, provided you give appropriate credit to the original author(s) and the source, provide a link to the Creative Commons license, and indicate if changes were made. The Creative Commons Public Domain Dedication waiver (http://creativecommons.org/ publicdomain/zero/1.0/) applies to the data made available in this article, unless otherwise stated. promoters in poultry farms for belief of their ability in enhancing growth performance, feed conversion rate, and prevention of the entry of bacterial microbes to poultry flocks has been led to global antimicrobial resistance. Searching for an alternative strategy to antibiotics becomes an urgent need to diminish their use in the poultry sector $[8,9]$.

Natural plant extract materials have been used as a traditional therapeutic remedy in many countries, especially in developing countries [10,11]. Peppermint oil (Mentha piperita L.) is extracted from the leaves of the peppermint plant using the steam distillation method $[11,12]$. Previous reports have displayed the antibacterial activity of the peppermint oil against different bacterial diseases, including C. perfringens $[12,13]$. Plant essential oils (EO) can be used in an emulsion form to increase their antibacterial activity $[14,15]$.

Microemulsions (MEs) are dispersions consisting of an oil phase, water phase, surfactant, and cosurfactant, which are single optically isotropic and thermodynamically stable liquid solutions with a droplet diameter usually within the range of 
10-100 nm [16,17]. The advantages of ME over traditional methods are spontaneous formation, thermodynamic stability, the simplicity of manufacture, and high-solubilization capacity for both lipophilic and hydrophilic compounds [18].

The aim of this study was to assess the efficacy of peppermint oil and peppermint oil ME in the control of necrotic enteritis disease in broiler chickens and studying their effect on performance.

\section{Materials and Methods}

Ethical approval

The experimental study was approved by the Ethical Committee of the Animal Health Research Institute, Ministry of Agriculture, Giza, Egypt.

\section{Study period and location}

The experimental study was conducted in July 2019 for four weeks (days 10 - 35) on 80 commercial 1-day-old Arbor Acres broiler chicken, that were randomly assigned to four groups (20 birds each). This study was conducted in Laboratory Animal Unit, Reference Laboratory for Veterinary Quality Control on Poultry Production (RLQP), Animal Health Research Institute Giza, Egypt. Characterization of peppermint oil ME was done in the Nanotechnology and Advanced Materials Central Laboratory, Agricultural Research center, Giza and in Central laboratory, Faculty of Agriculture, Cairo University.

\section{Preparation of $\boldsymbol{C}$. perfringens strain}

The percentage of necrotic enteritis was $34.7 \%$ (8/26), where $C$. perfringens was recorded in eight broiler chicken farms from 26 broiler chicken farms. $C$. perfringens strain (Type A) used in the experimental model was isolated from a field case broiler chicken farm suffering from necrotic enteritis. It was preserved in a brain heart infusion broth containing $25 \%$ glycerol at $-80^{\circ} \mathrm{C}$ according to Dar et al. [19], Wen and McClane [20]. Detection of the viability and purity of preserved frozen strain was done according to Tessari et al. [21] using selective enrichment cooked meat medium (Becton Dickinson and Company, Sparks, Maryland, USA), $10 \%$ sheep blood agar with neomycin $(40 \mu \mathrm{g} / \mathrm{mL})$ and tryptose-sulfite-cycloserine agar (TSC) plates , and anaerobic jar containing GasPakTM (Oxoid Limited, Thermo Fisher Scientific Inc., UK) anaerobic incubation. Confirmation of the $C$. perfringens colonies was done as described by Tessari et al. [21] using egg yolk agar plates containing 10\% Egg Yolk Emulsion (Oxoid Limited, Thermo Fisher Scientific Inc., UK) for detection of the lecithinase activity and litmus milk medium (Oxoid Limited, Thermo Fisher Scientific Inc., UK) for detection of the stormy fermentation reaction.

\section{Preparation of peppermint oil ME}

Peppermint oil was kindly purchased from CAPPHARM $^{\circledR}$, Cairo, Egypt which consists of carvone, menthol and menthone compound (sinod, kadenin, and limonen). Tween 80 was obtained from the Sigma-Aldrich Co.). Double-distilled and deionized water was filtered before use. Peppermint oil ME (oil in water) was prepared in the RLQP by phase titration method according to Rao and McClements [22] using peppermint oil ( $15 \mathrm{~mL})$, Tween $80(30 \mathrm{~mL})$, and distilled deionized water $(55 \mathrm{~mL})$.

\section{Characterization of peppermint oil ME}

Characterization of peppermint oil ME was done according to Hunter [23], Andrievsky et al. [24], and Seung et al. [25]. Zetasizer Malvern Instrument (Corp, Malvern, UK) was used to measure droplet size, surface charge (zeta potential), size distribution (polydispersity indexes $[\mathrm{PDI}]$ ), and electrical conductivity of the ME. Fourier transform infrared (FT/IR)-6100 spectrometer was used to determine the functional groups in the ME based on the bond vibration frequencies among atoms. High-resolution transmission electron microscopy (JEM 1400F HRTEM) was used to analyze the microemulsion shape and size at beam energy of $300 \mathrm{keV}$.

Characterization of peppermint oil and peppermint oil ME components using liquid chromatographymass spectrometry (LC-MS/MS)

Chemicals

HPLC grade formic acid was purchased from Merck (Darmstadt, Germany), whereas analytical grade methanol was purchased from Fisher scientific (Leicestershire, UK), Deionized water or HPLC grade water was obtained from Millipore Sigma (Burlington, MA, USA). A $0.45 \mathrm{~mm}$ disposable membrane filter was purchased from Cronus Filter (UK).

\section{Method}

The analysis was carried out in Animal Health Research Institute according to Kapp et al. [26] using an Agilent 1260 series (Agilent Co., Santa Clara, CA, USA). Quaternary pump equipped with vacuum degasser, autosampler, thermostatted column compartment, and UV diode array detector interfaced with an Applied Biosystems 4000 QTRAP LC/MS/MS system.

Determination of antibacterial activity of peppermint oil and peppermint oil ME against $C$. perfringens field strain (In vitro)

Antibacterial activity of the two tested chemicals (peppermint oil and peppermint oil ME) against $C$. perfringens Type A strain was assessed as described by Salvia-Trujillo et al. [14] and Clinical Microbiology and Infection [27] using the minimum inhibitory concentration (MIC) method. The lowest concentration that showed no bacterial growth had been recorded.

Anti clostridial effect of peppermint oil and peppermint oil ME in commercial broiler chicken model as a prevention trial

Four weeks experiment was conducted to assess the efficacy of peppermint oil and peppermint oil ME in prevention of necrotic enteritis in broiler chickens. 


\section{Experimental model design}

Eighty one-day-old unvaccinated male commercial Arbor Acres broiler chicks were randomly allocated into four groups (20 birds each) in battery cages in Laboratory Animal Unit (biosafety level two) with controlled light and ventilation system in RLQP. Chicks were provided with clean drinking water and weighted diets along the experimental period. A starter diet was administrated during 0 to 13 days, and a grower diet was fed afterward till day 35 . The feed met all the nutrient requirements of chicks according to NRC [28].

\section{Experimental protocol}

Experimental protocol was according to Eid et al. [29], with some modifications in the induced stress factor; before starting of the experiment, 10 chicks (extra than 80 chicks) and feed were exposed to bacterial investigation for $(E$. coli, Salmonella, and C. perfringens) using MacConkey, XLD, and sheep blood agar plates, respectively, and confirmed using different biochemical tests according to ISO6579-1 2017 [30], Dufour-Zavala [31], and Lovland et al. [32]. Chicks were assigned to four groups as group 1: Negative control, group 2: Positive control (C. perfringens), group 3: Peppermint oil $(0.5 \mathrm{~mL} / \mathrm{mL}$ water), and group 4: $\mathrm{ME}(0.25 \mathrm{~mL} / \mathrm{mL}$ water $)$ groups. All chicks in all groups were exposed to $12 \mathrm{~h}$ feed withdrawal time on day 13. Group I was administrated with $1 \mathrm{ml}$ of Brain heart infusion broth on days 14, 15, and 16. Groups (two, three, and four) were challenged with $1 \mathrm{~mL}\left(1 \times 10^{8}\right) C$. perfringens as three successive doses for days 14, 15, and 16. Groups (three and four) were treated with peppermint oil and peppermint oil $\mathrm{ME}$, respectively, through drinking water on day $10^{\text {th }}$ till the end of the experimental period $35^{\text {th }}$ day. The dose of peppermint oil and ME used in groups (three and four) was calculated according to results of the MIC.

\section{Laboratory examination}

Clinical signs and mortality were observed daily during the experiment. On days 21, 28, and 35 of the experiment, samples were taken from the intestine and liver for the examination of gross lesions as described by Tizhe et al. [33]. Furthermore, cecal samples were examined for $C$. perfringens counts using Reinforced clostridial agar plates as described by Brady [34]. Performance parameters was assessed according to Ensminger [35], and Barzegar et al. [36] through measurement of body weight (BW), body weight gain and feed conversion ratio (FCR) for each group during the experiment.

\section{Statistical analysis}

Statistical analysis was conducted using SPSS IBM 21 software, (IBM Corp., Armonk, NY) to evaluate the reduction of $C$. perfringens counts throughout the experimental groups using non-parametric tests (Kruskal-Wallis and Mann-Whitney tests). C. perfringens counts did not show a normal distribution according to Kolmogorov-Smirnov test $(n>50)$.
Furthermore, the differences in BW gain and FCR in different groups were analyzed using (oneway analysis of variance). Results of all tests used in this study were considered significant at $\mathrm{p} \leq 0.05$.

\section{Results}

\section{Preparation of $\boldsymbol{C}$. perfringens strain}

The colonies of $C$. perfringens were identified as double zone of hemolysis on sheep blood agar with neomycin medium and black colonies on TSC medium. Furthermore, suspected colonies were confirmed using biochemical tests and revealed positive lecithinase activity on egg yolk salt agar, positive stormy fermentation on litmus milk medium.

\section{Determination of antibacterial activity of peppermint oil and peppermint oil ME against $C$. perfringens field strain (In vitro)}

The efficacy of peppermint oil and peppermint oil ME against $C$. perfringens was evaluated using minimal inhibitory concentration method. The results revealed that the MICs of peppermint oil and peppermint oil $\mathrm{ME}$ were $0.5 \mathrm{~mL} / \mathrm{L}$ and $0.25 \mathrm{~mL} / \mathrm{L}$, respectively.

\section{Characterization of peppermint oil ME}

The peppermint oil ME (15\% oil/water) was characterized for the conductivity, viscosity, PDI, and zeta potential that revealed $0.0151 \mathrm{~ms} / \mathrm{cm}, 0.8872$, 0.234 , and $-24 \mathrm{mV} \pm 4.19$, respectively.

The results of HRTEM (Figure-1) revealed that peppermint oil ME had no aggregation, size homogeneity, and spherical nature. The average size of peppermint oil ME was $29.96 \mathrm{~nm} \pm 1.56$ The distinguish of FT-IR bands in ME versus peppermint oil was divided into two regions: 1) The fingerprint region in ME had vibration bands of $<1500 \mathrm{~cm}^{-1}: 1295.93 \mathrm{~cm}^{-1}$ and $1251.58 \mathrm{~cm}^{-1}$ for Ester carbonyl, phenol and phenyl, acryl C-O, respectively. $1251.58 \mathrm{~cm}^{-1}$ for strong C-O stretching of aromatic ester group, $945 \mathrm{~cm}^{-1}$ and $913 \mathrm{~cm}^{-1}$ for strong O-H bonding of carboxylic acids group 2) The group frequency region in ME had vibration band of $2102.99 \mathrm{~cm}^{-1}$ that assigned to weak $\mathrm{C} \Xi \mathrm{C}$ stretching of alkyne group. The FT-IR analysis of peppermint oil and ME exhibited same band pattern with different intensities below $1500 \mathrm{~cm}^{-1}$ : $\left(1458.29 \mathrm{~cm}^{-1}\right.$, $\left.1459.85 \mathrm{~cm}^{-1}\right)$ for $\mathrm{C}-\mathrm{H}$ bonding alkane of methylene group, (1035 and $1098.26 \mathrm{~cm}^{-1}$ ) for $\mathrm{C}-\mathrm{O}-\mathrm{C}$ bonding of secondary alcohol, and (1374.04 and $1354.75 \mathrm{~cm}^{-1}$ ) for phenol - alcohol groups, respectively. Peppermint oil and ME exhibited same band pattern with the same intensities in the group frequency region at a vibration band of 2923.56 that assigned to $\mathrm{CH} 3$ of alkanes. Furthermore, peppermint oil and ME exhibited same band pattern with different intensities in the group frequency region (3424 and $3438 \mathrm{~cm}^{-1}$ ) for $\mathrm{H}$ bonding and $\mathrm{O}-\mathrm{H}$ group of phenol and alcohol group, (2857.99 and $\left.2861.82 \mathrm{c}^{\mathrm{m}-} 1\right)$ for $\mathrm{C}-\mathrm{H}$ stretching of alkanes, (1748 and $1730 \mathrm{c}^{\mathrm{m}-} 1$ ) for $\mathrm{C}=\mathrm{O}$ stretching of carbonyl group, and (1630 and $\left.1639.2 \mathrm{c}^{\mathrm{m}-} 1\right)$ for N-H stretching of primary amines, respectively. (Table-1 and Figure-2). LC-MS/MS analysis of oil and ME revealed 


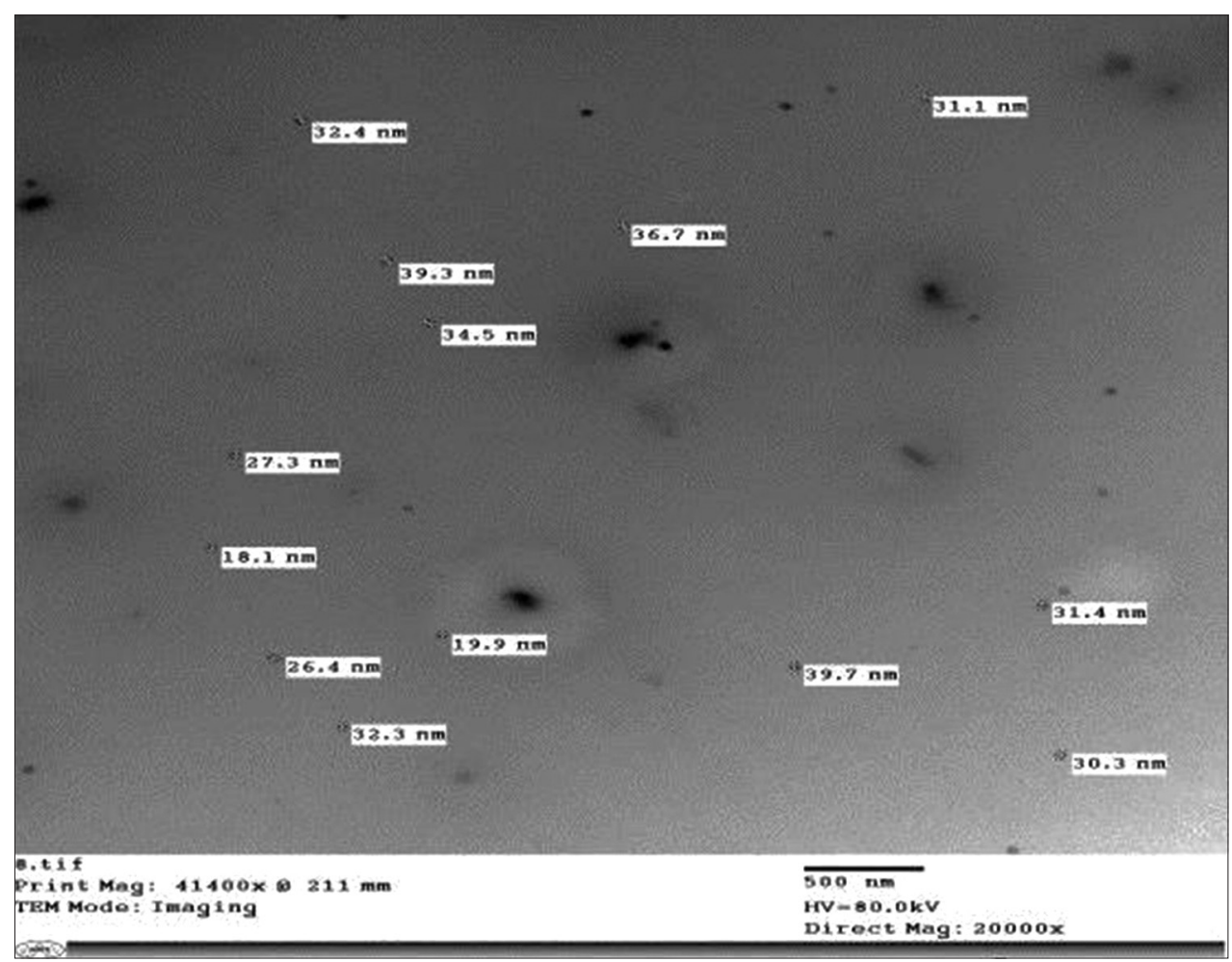

Figure-1: High-resolution transmission electron microscopy of peppermint microemulsion revealed that droplets size $29.96 \mathrm{~nm} \pm 1.56$, there are no aggregation, size homogeneity, and spherical nature.

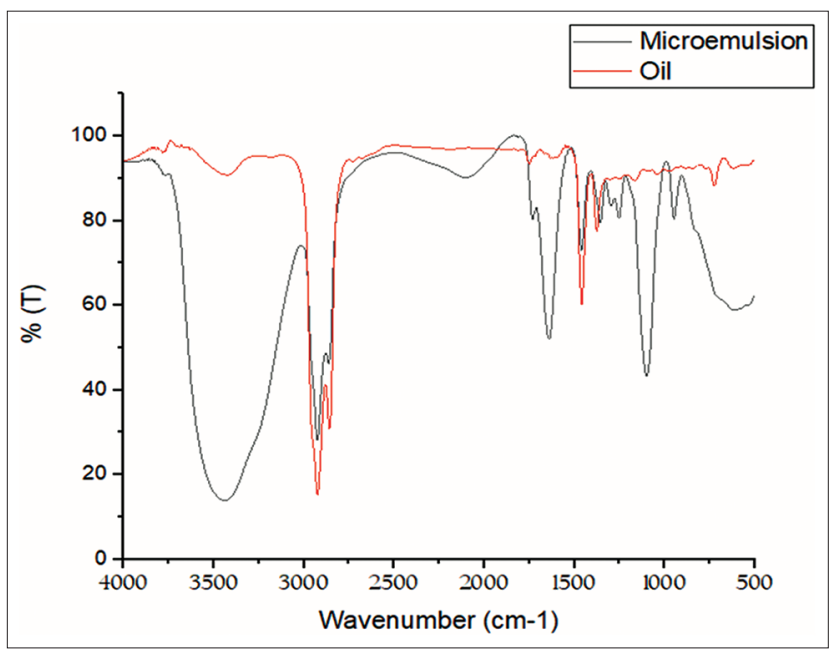

Figure-2: Fourier-transform infrared spectroscopy of peppermint oil and peppermint microemulsion.

common presence of some phenolic compounds such as rosmarinic $(360.31 \mathrm{~g} / \mathrm{mol})$ and chlorogenic acid $(354.31 \mathrm{~g} / \mathrm{mol})$, hesperidin $(610.56 \mathrm{~g} / \mathrm{mol})$ and luteolin $7-\mathrm{O}-\beta$-glucuronide $(462.1 \mathrm{~g} / \mathrm{mol})$ and non-phenolic compounds such as menthone $(154.25 \mathrm{~g} / \mathrm{mol})$., Tween $80(1309.68 \mathrm{~g} / \mathrm{mol})$ was only observed in the ME whereas Carvone (150.22 $\mathrm{g} / \mathrm{mol})$ was only observed in peppermint oil.

\section{Laboratory examination of the experimental model}

No signs were observed during the experimental period in negative control, peppermint oil and peppermint oil ME groups (one, three, and four). signs were only detected in the positive control group (two) within 4 to 21 days post-challenge including diarrhea,
Table-1: Fourier transform infrared spectroscopy described fingerprint bands of peppermint oil and microemulsion.

\begin{tabular}{|c|c|c|}
\hline $\begin{array}{l}\text { Microemulsion } \\
\text { bands }\end{array}$ & $\begin{array}{c}\text { Peppermint oil } \\
\text { bands }\end{array}$ & Functional groups \\
\hline - & 3781.72 & (-OH stretching) \\
\hline 3438 & 3424 & (-OH stretching) \\
\hline 2923.56 & 2923.56 & $\mathrm{CH} 3$ groups \\
\hline 2861.82 & 2857.99 & $\mathrm{CH} 2$ groups \\
\hline 2102.99 & - & $\begin{array}{l}\text { Weak C-C stretching } \\
\text { alkyne group }\end{array}$ \\
\hline 1730 & 1748 & C-O bonding \\
\hline 1639.2 & 1630 & $\begin{array}{l}\mathrm{N}-\mathrm{H} \text { stretching } \\
\text { primary amines }\end{array}$ \\
\hline 1459.85 & 1458.29 & $\begin{array}{l}\mathrm{C}-\mathrm{H} \text { bonding } \\
\text { methylene group }\end{array}$ \\
\hline 1354.75 & 1374.04 & $\begin{array}{l}\text { Phenol and alcohol } \\
\text { group }\end{array}$ \\
\hline 1295.93 & - & $\begin{array}{l}\text { Ester carbonyl group } \\
\text { and phenol }\end{array}$ \\
\hline 1251.58 & - & Phenyl and acryl C-O \\
\hline 1098.26 & 1035 & $\mathrm{C}-\mathrm{O}-\mathrm{C}$ bonding \\
\hline 945 & - & $\begin{array}{l}\mathrm{O}-\mathrm{H} \text { bond carboxylic } \\
\text { acids }\end{array}$ \\
\hline 913 & - & $\begin{array}{l}\mathrm{O}-\mathrm{H} \text { bond carboxylic } \\
\text { acids }\end{array}$ \\
\hline
\end{tabular}

reduction in body weight, emaciation and reluctance of movement (Table-2).

No gross changes were observed in peppermint oil and peppermint oil ME groups (groups three and four) in intestine and liver except distention of intestine with gases and enteritis on day 28 day. Gross lesions were observed in the positive control group (two) such as intestinal distension with gases, enteritis at 7-day post-challenge and increased at 14- and 


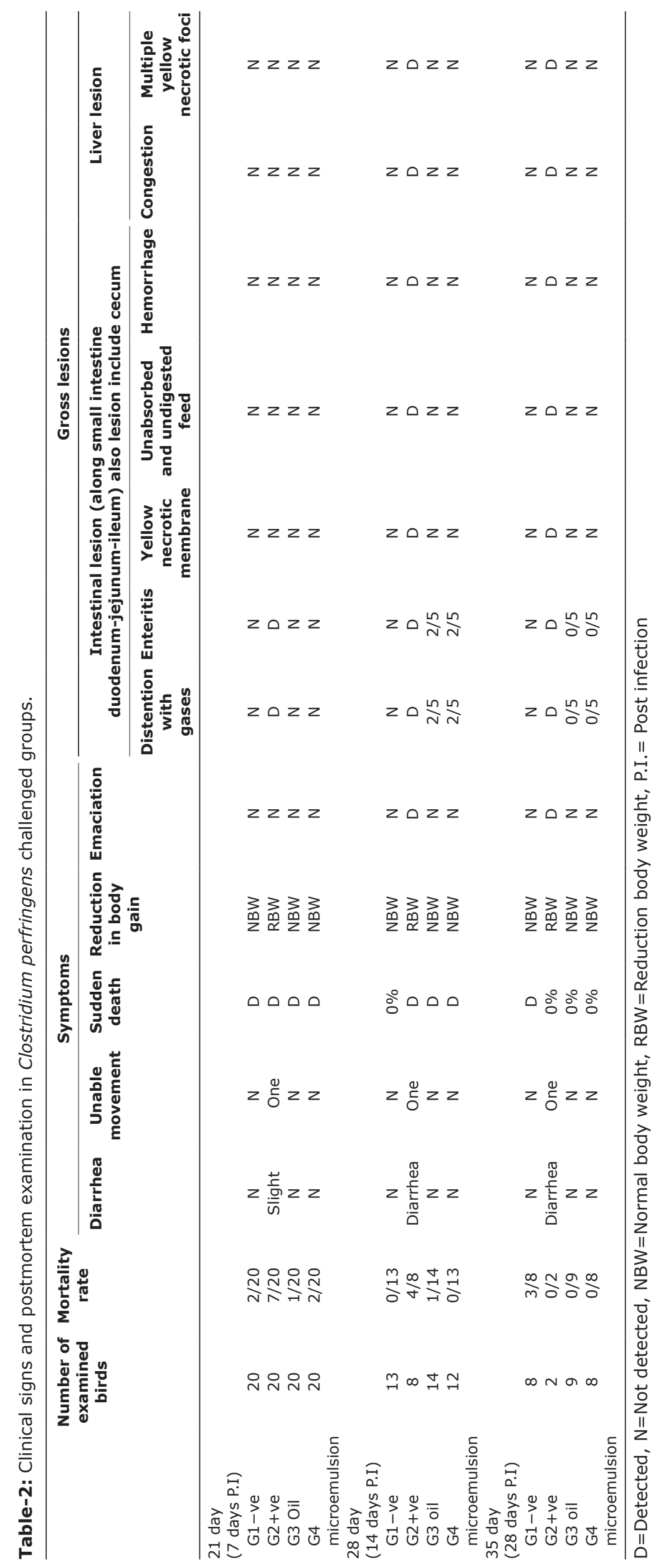


21-day post-challenge including enteritis, scattered necrotic foci along the mucosa, presence of yellow diphtheritic necrotic membrane, gaseous distention, hepatic congestion, multiple yellow necrotic foci in liver and presence of undigested feed (Table-2). Dead birds in the positive control group (group two) during the experimental period showed severe degree of gross lesions.

Treatment with peppermint oil and peppermint oil ME was reduced the mortality rate in the groups three and four to $10 \%(2 / 20)$ compared to the positive control group (II) that showed a high mortality rate of $55 \%(11 / 20)$ (Figure-3).

The peppermint oil and ME were most effective on day 35 of the experimental period resulting in a significant reduction of cecal $C$. perfringens counts in groups three and four by Kruskal - Wallis test $(\mathrm{p}<0.05)$ compared to the positive control group (group two) (Figure 4). There was no significant difference among the administration of peppermint and peppermint oil ME treatments by the Mann-Whitney test $(\mathrm{p}<0.05)$.

Treatments with peppermint oil and peppermint oil ME in groups three and four were significantly increased the BW gain, improve total feed intake and decrease FCR using one-way ANOVA test $(\mathrm{p}<0.05)$ compared to the positive control group (group two) (Tables-3 and 4).

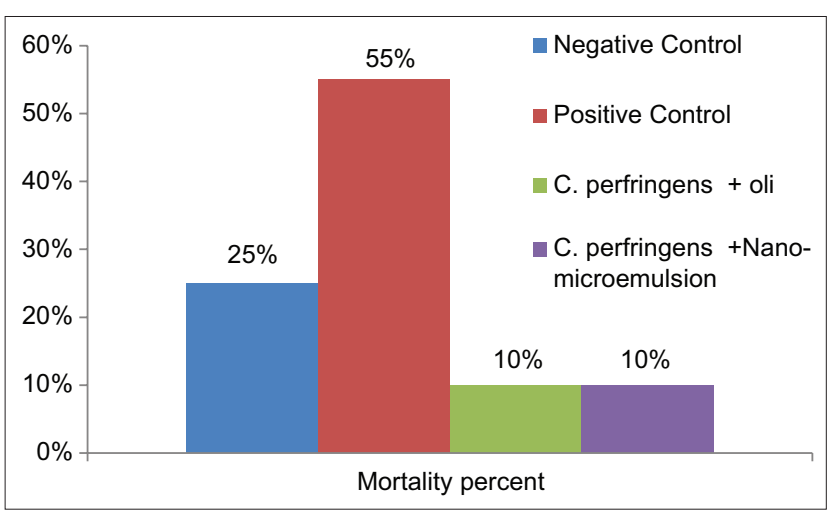

Figure-3: Mortality rate in broiler chickens during the experimental treatments.

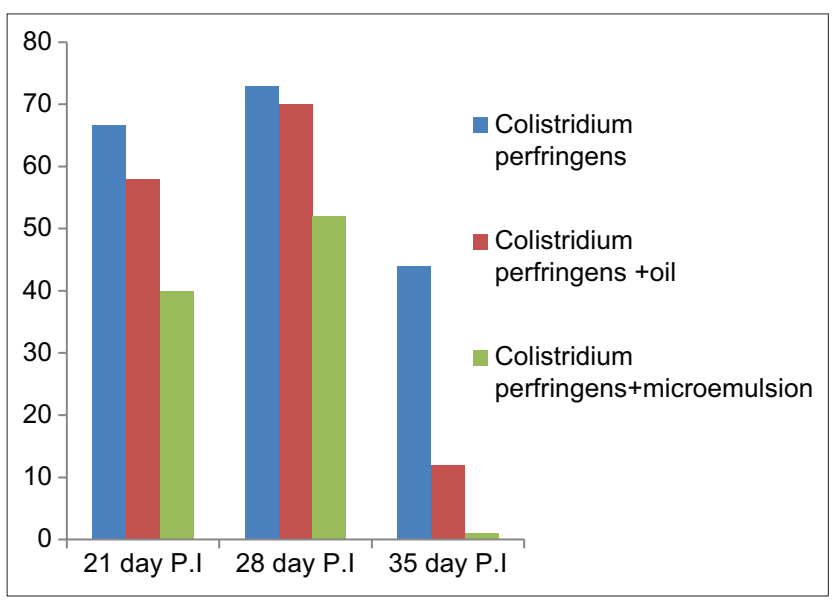

Figure-4: Quantitative determination of cecal Clostridium perfringens counts using Reinforced Clostridial agar. P.I.=Post infection.

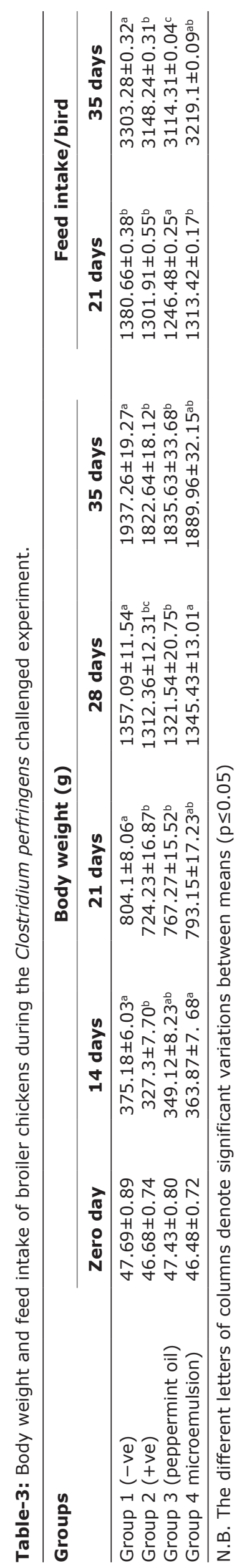


Table-4: Body weight gain and feed conversion rate of broiler chickens during the experimental treatments.

\begin{tabular}{|c|c|c|c|c|}
\hline \multirow[t]{2}{*}{ Group } & \multicolumn{2}{|c|}{ Body weight gain } & \multicolumn{2}{|c|}{ Feed conversion rate } \\
\hline & 21 days & 35 days & 21 days & 35 days \\
\hline Group 1 (-ve) & $756.41 \pm 17.49^{a}$ & $1889.57 \pm 43.25^{c}$ & $1.83 \pm 0.012^{\mathrm{b}}$ & $1.75 \pm 0.02^{\mathrm{a}}$ \\
\hline Group 2 (+ve) & $677.55 \pm 12.07^{c}$ & $1775.96 \pm 59.3^{a}$ & $1.92 \pm 0.03^{\mathrm{a}}$ & $1.77 \pm 0.014^{\mathrm{a}}$ \\
\hline Group 3 (peppermint oil) & $719.84 \pm 19.61^{b}$ & $1788.2 \pm 21.28^{a}$ & $1.73 \pm 0.04^{a}$ & $1.74 \pm 0.03^{a}$ \\
\hline Group 4 (microemulsion) & $746.67 \pm 6.73^{a}$ & $1843.48 \pm 26.63^{b}$ & $1.76 \pm 0.012^{b}$ & $1.75 \pm 0.018^{a}$ \\
\hline
\end{tabular}

N.B. The different letters of columns denote significant variations between means $(p \leq 0.05)$

\section{Discussion}

The characterization of peppermint oil and $\mathrm{ME}$ is a first step towards determining the efficacy of the peppermint oil and $\mathrm{ME}$ in the prevention of necrotic enteritis. Our peppermint oil ME formulation (15\% oil/water) have PDI, zeta potential, and droplet size of0.234, $-24 \mathrm{mV} \pm 4.19$ and $29.96 \pm 1.56 \mathrm{~nm}$, respectively that agree with Lv et al. [37] who reported similar observations regarding the lower droplet size and PDI of peppermint oil ME and this attributed to the type of surfactant used; tween $80(70 \mathrm{~nm})$ has a significant influence on droplet size and polydispersity index.

Marcela et al [38] has displayed that peppermint oil ME formulation (30\% oil/water) had particle size, conductivity, viscosity, PDI, and zeta potential of $12.66 \pm 0.54 \mathrm{~nm}, 60.0 \pm 3.3 \mu \mathrm{S} / \mathrm{cm}, 3.58,0.265$, and $-4.35 \mathrm{mV} \pm 4.19$, respectively. The infrared spectra of peppermint oil and ME after infusion mainly exhibited same band pattern representing phenolic and non-phenolic compounds indicating that no noticeable changes occurred during the formulation.

The anticlostridal activity of peppermint oil and ME observed in this study agrees with a previous report of Encun et al. [39] who displayed the antimicrobial activity of peppermint EO against $C$. perfringens in vitro and in vivo. Our study shows that a high BW gain was observed in both treated groups 3 and 4. Similarly some EO products revealed antimicrobial activity against $C$. perfringens and had the ability to elevate productive performance in poultry [40].

The severity of signs, gross lesions and mortalities observed in the challenged chickens with $C$. perfringens $\left(1 \times 10^{8}\right)$ in the positive control group (group 2) may be attributed to the dietary stress factor induced through the application of feed withdrawal period of 12 hours on day 13. These findings agree with a previous report of Redondo et al. [5] who displayed the application of feed withdrawal in birds challenged with $C$. perfringens type A strain develops severe gross lesions in $70 \%$ of challenged birds.

On the other hand, a study by Olkowski et al. [41] has displayed the subclinical form of necrotic enteritis in the challenged chickens with $C$. perfringens Furthermore, Our study displayed the reduction of the severity of signs lesions and mortalities in both treated groups with $\mathrm{ME}$ and peppermint oil, this agrees with results reported by Timbermont et al. [42] and Jerzsele et al. [43] who displayed the addition of
EO can lead to a decrease in morbidity percentage in birds developing necrotic lesions in the gut, increase BW gain, and diminish postmortem lesions compared to the control group.

A study by Ameri et al. [44] has displayed that broilers whose diets were supplemented with peppermint powder had higher BW on day 42 . Feed supplementation with a blend of peppermint and eucalyptus EO improved the immune status and performance of broiler chickens infected with the Newcastle disease virus, and increased their final BW, decreased final FCR, and total mortality [45]. The performance of broilers whose diets were supplemented with different doses of dry peppermint was observed with a higher weekly WG and lower FCR in chicks that were fed with a lower $(0.5 \%)$ than a higher $(1.5 \%)$ peppermint dose [46]. The increase BW gain and lower FCR observed in this study in broiler chickens fed the peppermint diet in groups three and four may be related to the digestibility and gut microbial balancer characteristics of menthol that stimulate the secretion of endogenous digestive enzymes, and improving poultry growth [47].

Diets containing peppermint leaves were reported to improve the growth performance of broiler chicks at early stages of life [48].

Furthermore, the supplementation of dried Mentha pulegium at $5 \mathrm{~g} / \mathrm{kg}$ improved growth performance of broilers on day 42 [49]. BW, BW gain, and FCR were significantly increased $(\mathrm{p}<0.05)$ for broilers fed on $1.5 \%$ peppermint leaves compared to the control group [50]. On the other hand, a reported case [51] has revealed that the supplementation of dried Mentha cordifolia at concentrations of $0.5 \%, 1.0 \%, 1.5 \%$, and $2.0 \%$ had no significant effect on the growth performance of broilers on day 42 . The results of this study support the observations of Spirling and Daniels [52] who reported that peppermint has a positive effect on digestion and can strongly improve feed intake.

Our study has displayed the reduction of cecal C. perfringens count in both treated groups with peppermint oil $\mathrm{ME}$ and peppermint oil compared to the positive control group which agrees with previous reports [53-56] that displayed the use of some EO decreased $C$. perfringens counts in poultry.

\section{Conclusion}

Our study suggests the potential use of peppermint oil and ME in the reduction of necrotic enteritis lesions and $C$. perfringens count. 


\section{Authors' Contributions}

HKS and RAH performed all bacteriological work. DMAE performed preparation and characterization of microemulsion, designed and coordinated the study. HKS, RAH, and DMAE designed the work and performed the experiment. RAH and DMAE performed all statistical analysis and wrote the manuscript. All authors read and approved the final manuscript.

\section{Acknowledgments}

The authors would like to acknowledge and thank Dr. Ahmed Fathy for his help in the random allocation in the experimental model. The authors declare that they did not receive any funds for this study.

\section{Competing Interests} interests.

The authors declare that they have no competing

\section{Publisher's Note}

Veterinary World remains neutral with regard to jurisdictional claims in published institutional affiliation.

\section{References}

1. Kaldhusdal, M., Schneitz, C., Hofshagen, M. and Skjerve, E. (2001) Reduced incidence of Clostridium perfringens-associated lesions and improved performance in broiler chickens treated with normal intestinal bacteria from adult fowl. Avian Dis., 45(1): 149-156.

2. Immerseel, V.F., De Buck, J., Pasmans, F., Huyghebaert, G., Haesebrouck, F. and Ducatelle, R. (2004) Clostridium perfringens in poultry: An emerging threat for animal and public health. Avian Pathol., 33(6): 537-549.

3. Cooper, K.K. and Songer, J.G. (2009) Necrotic enteritis in chickens: A paradigm of enteric infection by Clostridium perfringens Type A. Anaerobe, 15(1-2): 55-60.

4. Lyhs, U., PerkoMäkelä, P., Kallio, H., Brockmann, A., Heinikainen, S., Tuuri, H. and Pedersen, K. (2013) Characterization of Clostridium perfringens isolates from healthy Turkeys and from Turkeys with necrotic enteritis. Poult. Sci., 92(7): 1750-1757.

5. Redondo, L.M., Redondo, E.A., Delgado, F., La Sala, L.F. and Miyakawa, M.E.F. (2016) An experimental reproduction of necrotic enteritis in broiler chickens. J. Vet. Sci. Med., 4(1): 1-5.

6. William, R.B. (2005) Intercurrent coccidiosis and necrotic enteritis of chickens: Rational, integrated disease management by maintenance of gut integrity. Avian Pathol., 34(3): 159-180.

7. Shojadoost, B., Vince, A.R. and Prescott, J.F. (2012) The successful experimental induction of necrotic enteritis in chickens by Clostridium perfringens: A critical review. Vet. Res., 43(1): 74.

8. Dahiya, J.P., Wilkie, D.C., Van Kessel, A.G. and Drew, M.D. (2006) Potential strategies for controlling necrotic enteritis in broiler chickens in post-antibiotic era. Anim. Feed Sci. Technol., 129(1-2): 60-88.

9. Huyghebaert, G., Ducatelle, R. and Van Immerseel, F. (2011) An update on alternatives to antimicrobial growth promoters for broilers. Vet. J., 187(2): 182-188.

10. World Health Organization. (2004) WHO Guidelines on Safety Monitoring of Herbal Medicines in Pharmacovigilance Systems. World Health Organization, Geneva.
11. Mathur, A., Prasad, G.B.K., Rao, N., Babu, P. and Dua, V.K. (2011) Isolation and identification of antimicrobial compound from Mentha pipirita. Rasayan J., 4(1): 36-42.

12. Li, J., Dong, J., Qiu, J.Z., Wang, J.F., Luo, M.J., Li, H.E., Leng, B.F., Ren, W.Z. and Deng, X.M. (2011) Peppermint oil decreases the production of virulence-associated exoproteins by Staphylococcus aureus. Molecules, 16(2): 1642-1654.

13. Radaelli, M., Silva, B.P., Weidlich, L., Hoehne, L., Flach, A., Costa, L.A. and Ethur, E.M. (2016) Antimicrobial activities of six essential oils commonly used as condiments in Brazil against Clostridium perfringens. Braz. J. Microbiol., 47(2): 424-430.

14. Salvia-Trujillo, L., Rojas-Graü, A., Soliva-Fortuny, R. and Martín-Belloso, O. (2015) Physicochemical characterization and antimicrobial activity of food-grade emulsions and nanoemulsions incorporating essential oils. Food Hydrocolloids, 43(1): 547-556.

15. Valizadeh, A., Shirzad, M., Esmaeili, F. and Amani, A. (2018) Increased antibacterial activity of cinnamon oil microemulsionin comparison with cinnamon oil bulk and nanoemulsion. Nanomed. Res. J., 3(1): 37-43.

16. Jain, S., Jain, A.K., Pohekar, M. and Thanki, K. (2013) Novel self-emulsifying formulation of quercetin for improved in vivo antioxidant potential: Implications for drug-induced cardiotoxicity and nephrotoxicity. Free Radic. Biol. Med., 65(12): 117-130.

17. Zhang, J., Lv, Y., Wang, B., Zhao, S., Tan, M. and Lv, G. (2015) Influence of microemulsion-mucin interaction on the fate of microemulsions diffusing through pig gastric mucin solutions. Mol. Pharm., 12(3): 695-705.

18. Thirapit, S. and Tanasait, N. (2017) Development of a novel microemulsion for oral absorption enhancement of all-trans retinoic acid. Int. J. Nanomed., 12(8): 5585-5599.

19. Dar, P.S., Wani, S.A., Wani, A.H., Hussain, I., Maqbool, R., Ganaie, M.Y., Kashoo, Z.A. and Qureshi, S. (2017) Isolation, identification and molecular characterization of Clostridium perfringens from poultry in Kashmir valley, India. J. Entomol. Zool. Stud., 5(5): 409-414.

20. Wen, Q. and McClane, B.A. (2004) Detection of enterotoxigenic Clostridium perfringens Type A isolates in American retail foods. Appl. Environ. Microbiol., 70(5): 2685-2691.

21. Tessari, E.N.C., Cardoso, A.L.S., Kanashiro, A.M.I., Stoppa, G.F.Z, Luciano, R.L. and Castro, A.G.M. (2014) Analysis of the presence of Clostridium perfringens in feed and raw material used in poultry production. Food Nutr. Sci., 5(7): 614-617.

22. Rao, J. and McClements, D.J. (2011) Formation of flavor oil microemulsions, nanoemulsions and emulsions: Influence of composition and preparation method. J. Agric. Food Chem., 59(9): 5026-5035.

23. Hunter, R.J. (1981) Zeta Potential in Colloid Science, Principles and Applications. Academic Press, London.

24. Andrievsky, G.V., Klochkov, V.K., Bordyuh, A.B. and Dovbeshko, G.I. (2002) Comparative analysis of two aqueous colloidal solutions of C60 fullerene with help of FTIR reflectance and UV-Vis spectroscopy. Chem. Phys. Lett., 364(1-2): 8-17.

25. Seung, J.Y., Ramchandra, P., Jeung, S.A. and Hwa, M.K. (2009) Study on the size of fullerene (C60) aggregates in solution by photoluminescence and HRTEM measurements. J. Korean Phys. Soc., 55(1): 322-326.

26. Kapp, K., Hakala, E., Püssa, T., Orav, A., Raal, A. and Hanski, L. (2013) Polyphenolic composition and antichlamydial effect of commercial peppermint (Mentha x piperita L.) teas. Plant. Med., 79(13): WS11.

27. Clinical Microbiology and Infection. (2003) Determination of minimum inhibitory concentrations (MICs) of antibacterial agents by broth dilution. Clin. Microbiol. Infect., 9(8): 9-15.

28. NRC (1994) Nutrient Requirements of Poultrym, Ninth Revised Edition, National Academy Press, Washington DC. 
29. Eid, N.M., Dahshan, H.M., El-Nahass, S., Shalaby, B. and Ali, A. (2018) Anticlostridial activity of the thyme and clove essential oils against experimentally induced necrotic enteritis in commercial broiler chickens. Vet. Sci. Res. Rev., 4(1): 25-34.

30. ISO6579-1 (2017) Microbiology of the food chain-horizontal method for the detection, enumeration and serotyping of Salmonella-part 1: detection of Salmonella spp. International Organization for Standardization, Geneva.

31. Dufour-Zavala, L. (2008) A Laboratory Manual for the Isolation, Identification, and Characterization of Avian Pathogens. American Association of Avian Pathologists, San Diego.

32. Lovland, A., Kaldhusdal, M., Redhead, K., Skjerve, E. and Lillehaug, A. (2004) Maternal vaccination against subclinical necrotic enteritis in broilers. Avian Pathol., 33(1): 81-90.

33. Tizhe, J.Q., Bello, M., Kabir, J., Jasini A.M. and Nkrumah, J.L. (2015) Isolation and biochemical identification of Clostridium perfringens from raw beef sold in retail outlets in Zaria Metropolis, Nigeria. Int. J. Curr. Microbiol. Appl. Sci., 4(11): 23-29.

34. Brady, W.L. (1968) Measurements of some poultry performance parameter. Vet. Rec., 88: 245-260.

35. Ensminger, M.E. (1980) Poultry Science. $2^{\text {nd }}$ ed. ed. ISBN 10: 0813420873/ISBN 13: 9780813420875 . Published by Interstate Publishers, Incorporated, 1980, United States.

36. Barzegar, H., Mehrnia, M.A., Nasehi, B. and Alipour, M. (2018) Fabrication of peppermint essential oil nanoemulsions by spontaneous method: Effect of preparing conditions on droplet size. Flav. Fragr. J., 33(5): 351-356.

37. Lv, X., Liu, T., Ma, H., Tian, Y., Li, L., Li, Z., Gao, M., Zhang, J. and Tang, Z. (2017) Preparation of essential oilbased microemulsions for improving the solubility, $\mathrm{pH}$ stability, photostability, and skin permeation of quercetin. AAPS PharmSciTech, 18(8): 3097-3104.

38. Marcela, R., Bárbara, P.S., Luciana, W., Lucélia, H., Adriana, F., Luiz, A.M., Alves, C. and Eduardo, M.E. (2016) Antimicrobial activities of six essential oils commonly used as condiments in Brazil against Clostridium perfringens. Braz. J. Microbiol., 47(2): 424-443.

39. Encun, D.U., Liping, G., Zhui, L., Weiwei, W., Dan, L. and Yuming, G. (2015) In vitro antibacterial activity of thymol and carvacrol and their effects on broiler chickens challenged with Clostridium perfringens. J. Anim. Sci. Technol., 6(1): 58 .

40. Diaz Carrasco, J.M., Redondo, L.M., Redondo, E.A., Dominguez, J.E., Chacana, A.P. and Miyakawa, M.E.F, (2016) Use of plant extracts as an effective manner to control Clostridium perfringens induced necrotic enteritis in poultry. Biomed Res. Int., 2016(8): 3278359.

41. Olkowski, A.A., Wojnarowicz, C., Chirino-Trejo, M. and Drew, M.D. (2006) Responses of broiler chickens orally challenged with Clostridium perfringens isolated from field cases of necrotic enteritis. Res. Vet. Sci., 81(1): 99-108.

42. Timbermont, L., Lanckriet, A., Dewulf, J., Nollet, N., Schwarzer, K., Haesebrouck, F., Ducatelle, R. and Van Immerseel, F. (2010) Control of Clostridium perfringens-induced necrotic enteritis in broilers by target-released butyric acid, fatty acids and essential oils. Avian Pathol., 39(2): 117-121.
43. Jerzsele, A., Szeker, K., Csizinszky, R., Gere, E., Jakab, C., Mallo, J.J. and Galfi, P. (2012) Efficacy of protected sodium butyrate, a protected blend of essential oils, their combination, and Bacillus amyloliquefaciens spore suspension against artificially induced necrotic enteritis in broilers. Poult. Sci., 91(4): 837-843.

44. Ameri, S.A., Samadi, F., Dastar, B. and Zerehdaran, S. (2016) Effect of peppermint (Mentha piperita) powder on immune response of broiler chickens in heat stress. Iran. J. Appl. Anim. Sci., 6(2): 435-445.

45. Awaad, M.H.H., Afify, M.A.A., Zoulfekar, S.A., Mohammed, F.F., Elmenawy, M.A. and Hafez, H.M. (2016) Modulating effect of peppermint and eucalyptus essential oils on VND infected chickens. Pak. Vet. J., 36(3): 350-355.

46. Al-Kassie, G.A.M. (2010) The role of peppermint (Mentha piperita) on performance in broiler diets. Agric. Biol. J. North Am., 1(5): 1009-1013.

47. Cross, D.E., McDevitt, R.M., Hillman, K. and Acamovic, T. (2007) The effect of herbs and their associated essential oils on performance, dietary digestibility and gut microflora in chickens from7 to 28 days of age. Br. Poult. Sci., 48(4): 496-506.

48. Toghyani, M., Toghyani, M., Gheisari, A., Ghalamkari, G. and Mohammadrezaei, M. (2010) Growth performance, serum biochemistry and blood hematology of broiler chicks fed different levels of black seed (Nigella sativa) and peppermint (Mentha piperita). Livest. Sci., 129(1-3): 173-178.

49. Nobakht, A., Shivazad, M., Chamany, M. and Safameher, A.R. (2006) The effects of dietary electrolyte balance on performance of laying hens exposed to heatstress environment in late laying period. Int. J. Poult. Sci., 5(10): 955-958.

50. Gurbuz, Y. and Ismael, I.A. (2016) Effect of peppermint and basil as feed additive on broiler performance and carcass characteristics. Iran. J. Appl. Anim. Sci., 6(1): 149-156.

51. Khempaka, S., Pudpila, U. and Molee, W. (2013) Effect of dried peppermint (Mentha cordifolia) on growth performance, nutrient digestibility, carcass traits, antioxidant properties, and ammonia production in broilers. J. Appl. Poult. Res., 22(4): 904-912.

52. Spirling, L.I. and Daniels, I.R. (2001) Botanical perspectives on health peppermint: More than just an after-dinner mint. J. R. Soc. Promot. Health, 121(1): 62-63.

53. Engberg, R.M., Grevsen, K. and Ivarsen, E. (2012) The effect of Artemisia annua on broiler performance, on intestinal microbiota and on the course of a Clostridium perfringens infection applying a necrotic enteritis disease model. Avian Pathol., 41(4): 369-376.

54. Cho, J.H., Kim, H.J. and Kim, I.H. (2014) Effects of phytogenic feed additive on growth performance, digestibility, blood metabolites, intestinal microbiota, meat color and relative organ weight after oral challenge with Clostridium perfringens in broilers. Livest. Sci., 160(1): 82-88.

55. Du, E., Gan, L., Li, Z., Wang, W., Liu, D. and Guo, Y. (2015) In vitro antibacterial activity of thymol and carvacrol and their effects on broiler chickens challenged with Clostridium perfringens. J. Anim. Sci. Technol., 6(1): 58.

56. Yang, Y., Wang, Q., Diarra, M.S., Yu, H., Hua, Y. and Gong, J. (2016) Functional assessment of encapsulated citral for controlling necrotic enteritis in broiler chickens. Poult. Sci., 95(4): 780-789. 